\title{
Activities of Antitussive of even Alkaloids from Bulbus Fritillariae cirrhosae
}

Dongdong Wang*, Shu Wang and Wenhua Chen

Department of Pharmacogonosy, West China College of Pharmacy, Sichuan University, No.17, Duan 3, Renmin Nan Road, Chengdu 610041, P. R. China

\begin{abstract}
The objective of this study was to isolate active alkaloids from the Bulbus Fritillariae Cirrhosae (BFC), to evaluate their anti-tussive to find the highly active substance from the BFC for further new drug development. Materials and methods: The BFC was extracted with chloroform: methanol and alkaloids were isolated by phytochemical methods. The anti-tussive activity was investigated using ammonia induced mice coughing. Results: The seven alkaloids (1) (7) were isolated from the BFC and the structure were determined. The seven alkaloids significantly inhibited mice's frequency of cough induced by ammonia, increased mice's latent period of cough and show activity dose-dependently. The inhibitions of cough number of these alkaloids are $65.33 \%(1), 60.28 \%(2), 35.06 \%(3), 37.26 \%(4), 56.37 \%(5)$, $57.80 \%(6), 59.07 \%(7)$. The results of the present study provide a convincing proof to put BFC as one of the most popular antitussive Traditional Chinese Medicine (TCM) in China.
\end{abstract}

\section{Keywords: Antitussive; Alkaloids; Bulbus Fritillariae Cirrhosae}

\section{Introduction}

Coughing is a symptom of respiratory illness which causes chest and thorax pain [1]. Presently available therapies to treat cough are limited for lack of effective and safe medications. Moreover, most existed antitussive drugs could bring inevitable or intolerable side effects [2]. In TCM, many plants are recorded to treat respiratory complaints such as cough, bronchial inflammation, pneumonia and expectoration [3], which have been used for hundreds of years. So it is a noticeable path to search for effective medicines to treat cough in the rich traditional Chinese medicine in the world [4].

BFC, is a well known antitussive TCM used for a long time. It has been used in clinic for more than 2000 years in China due to the positive potent therapeutic effects, low toxicity and minimal side effects. The pharmacological studies indicate that the crude alkaloids extract of BFC have good antitussive activities $[5,6]$. Alkaloids were established to be the major biologically active components in the genus of Fritillaria. BFC which has been considered as the most valuable medicine in the genus of Fritillaria lacks further phytochemical study and pharmacological research of monomers of alkaloids in vivo. So we focused our studies on the phytochemical and pharmacological research on BFC. The isolation of alkaloids, evaluation of the antitussive activities of different alkaloids are the subject of this paper.

\section{Materials and Methods}

\section{Plant materials}

The Bulbs of Fritillariae Cirrhosae was collected in April 2010 in Chengdu International Trade City Hehuachi Chinese Medicinal Herbal Market, Chengdu city, Sichuan province, China. The BFC was authenticated by Dr. Wang Shu, Professor in Department of Pharmacogonosy, West China College of Pharmacy, Sichuan University. The voucher specimen was deposited in the herbarium of West China College of Pharmacy, Sichuan University.

\section{Extraction and isolation}

Dried ground bulbs (15 kg) were powdered and treated in ammonia (1200 ml) for 15 hours, then extracted with chloroform to obtain crude extract ( $38 \mathrm{~g}$ ). TAF was obtained by using previously described methods $[7,8]$. The concentrated extract was dissolved in $3 \%$ $\mathrm{HCl}$ and partitioned with chloroform. The $\mathrm{pH}$ of the aqueous solution was readjusted with $\mathrm{NH}_{4} \mathrm{OH}$ to 10.0 and extracted with $\mathrm{CHCl}_{3}$. The
$\mathrm{CHCl}_{3}$ extract (crude alkaloid, $9.5 \mathrm{~g}$ ) and was chromatographed over Si gel using petroleum ether-acetone-diethylamine (6:1:2 1: 1:2) of increasing polarity as eluent to obtain seven fractions [9].

\section{Animals and administration}

Kunming mice (18-22 g) were purchased from Experimental Animal Center, West China College of Pharmacy, Sichuan University (Chengdu, China). All animals were housed at room temperature (22$24^{\circ} \mathrm{C}$ ) and constant humidity $(40-70 \%)$ under a $12 \mathrm{~h}$ light-dark cycle and provided with food and water ad libitum.

After 3-5 days of adaptation, the eligible animals were randomly assigned to nine groups and orally administered, including group 1 (Control) (0.5\% carboxyl methylcellulose solution, $0.2 \mathrm{ml} / 20 \mathrm{~g}$ ), group 2 (the positive control) (codeine phosphate $/ 30 \mathrm{mg} / \mathrm{kg}$ ), group 3-9 (alkaloid (1 (7), respectively). The doses of the group 3-9 in the antitussive test were $3.0 \mathrm{mg} / \mathrm{kg}$.

\section{Anti-tussive activity}

Kunming mice were randomly divided into 9 groups of 6 each and administered according to Section 2.3. Anti-tussive activity was investigated on a classical mouse cough model induced by ammonia liquor [10,11]. Briefly, each mouse was placed in a $1000 \mathrm{ml}$ special glass chamber and exposed to, $0.3 \mathrm{ml} 25 \% \mathrm{NH}_{4} \mathrm{OH}$ for 45 seconds. Then the frequency of the cough for $5 \mathrm{~min}$ and latent period of cough were observed. The number of coughs produced $60 \mathrm{~min}$ after the administration of antitussive agents $\left(\mathrm{C}_{\mathrm{t}}\right)$ was compared with the number of control coughs $\left(\mathrm{C}_{0}\right)$. The antitussive effect was expressed as the percentage of inhibition of the number of control coughs $\left[\left(\mathrm{C}_{0}-\mathrm{C}_{\mathrm{t}}\right) /\right.$ $\left.\mathrm{C}_{0} \times 100 \%\right]$.

\section{Statistical analysis}

The experimental results are expressed as mean \pm standard error

*Corresponding author: Dongdong Wang, Department of Pharmacogonosy West China College of Pharmacy, Sichuan University, No. 17, Duan 3, Renmin Nan Road, Chengdu 610041, P. R. China, Tel: +86-028-85503950; Fax: +86028-85503950; E-mail: wddong1988@hotmail.com

Received May 29, 2014; Accepted August 18, 2014; Published August 20, 2014

Citation: Wang D, Wang S, Chen W (2014)Activities of Antitussive of even Alkaloids from Bulbus Fritillariae cirrhosae. Nat Prod Chem Res S1:005. doi:10.4172/23296836.S1-005

Copyright: ( 2014 Wang D, et al. This is an open-access article distributed under the terms of the Creative Commons Attribution License, which permits unrestricted use, distribution, and reproduction in any medium, provided the original author and source are credited. 
Citation: Wang D, Wang S, Chen W (2014) Activities of Antitussive of even Alkaloids from Bulbus Fritillariae cirrhosae. Nat Prod Chem Res S1:005. doi:10.4172/2329-6836.S1-005

Page 2 of 2

\begin{tabular}{|c|c|c|c|c|c|}
\hline Group & Dose $(\mathrm{mg} / \mathrm{kg})$ & No. of animals & Latent period of cough(s) & No. of coughs & Inhibition (\%) \\
\hline $0.5 \% \mathrm{CMC}-\mathrm{Na}$ & - & 6 & $15.73 \pm 2.74$ & $63.77 \pm 9.16$ & - \\
\hline Codeine Phosphate & 30 & 6 & $26.62 \pm 3.16^{*}$ & $19.18 \pm 3.98^{\star \star \star}$ & 69.92 \\
\hline$(1)$ & 3 & 6 & $34.19 \pm 6.55^{*}$ & $22.11 \pm 6.58^{* *}$ & 65.33 \\
\hline (2) & 3 & 6 & $59.23 \pm 8.31^{* *}$ & $25.33 \pm 5.81^{* *}$ & 60.28 \\
\hline (3) & 3 & 6 & $39.24 \pm 5.40^{*}$ & $41.41 \pm 8.21^{*}$ & 35.06 \\
\hline (4) & 3 & 6 & $43.25 \pm 6.71^{*}$ & $40.01 \pm 9.38^{*}$ & 37.26 \\
\hline (5) & 3 & 6 & $30.22 \pm 5.65^{*}$ & $27.82 \pm 7.37^{\star *}$ & 56.37 \\
\hline (6) & 3 & 6 & $58.47 \pm 10.31^{* *}$ & $26.91 \pm 6.80^{\star *}$ & 57.80 \\
\hline (7) & 3 & 6 & $46.79 \pm 8.49^{* *}$ & $26.10 \pm 6.00^{* * *}$ & 59.07 \\
\hline
\end{tabular}

Values expressed as mean \pm S.E.M. $(n=10)$

${ }^{*} \mathrm{P}<0.05$ for comparison of treated groups with control

** $\mathrm{P}<0.01$ for comparison of treated groups with control

${ }^{* * *} \mathrm{P}<0.001$ for comparison of treated groups with control

Table 1: Effects of alkaloids of medium dose on the ammonia liquor induced cough in mice.

of mean (S.E.M.). One-way analyses of variance (ANOVA) test was performed for multiple group comparison and Student's t-test was carried out for direct comparison of two groups. Values of $\mathrm{p}<0.05$ imply significance of the pharmacological effects in the experiments.

\section{Results}

\section{Alkaloids from BFC}

Alkaloids (1) (7) were isolated from BFC and identified on the basis of spectral data (1H-, 13C-NMR, IR, and mass spectra etc.).

\section{Effect of alkaloids on the ammonia liquor induced cough in mice}

The effects of the alkaloids on the ammonia liquor induced cough in mice are shown in Table 1. All alkaloids showed potent anti-tussive effects. Positive and tested groups could enhance latent period of cough and all the increase presented significantly, compared with the period of Control.

\section{Discussion and Conclusion}

The BFC is one of the most popular antitussive and expectorant TCM in Chinese communities. Potent antitussive, expectorant and antiasthmatic activities of the crude alkaloids extract from BFC were previously reported in the pharmacological studies $[5,6,12]$. In one word, the traditional knowledge and available clinical efficiency led us to isolate and characterize the active constituents present in BFC. In the present study, seven alkaloids were isolated from BFC.

In conclusion, the results of the present study provide a convincing proof to put $\mathrm{BFC}$ as one of the most popular antitussive and expectorant TCM in Chinese communities. Through the pharmacological evaluation on antitussive, expectorant and anti-inflammatory activities of all alkaloids respectively, (1), (2), (5), (6), (7) were highly active constituents of crude alkaloids extract from BFC. The mechanism of action explained for the observed activities have not been established, and thus further investigation needs conducted.

\section{References}

1. Irwin RS, Madison JM (2000) The diagnosis and treatment of cough. N Engl J Med 343: 1715-1721.

2. Zhang JX, Lao A, Xu RS (1933) Steroidal alkaloids from Fritillaria thunbergii var. chekiangensis. Phytochemistry 33: 946-947.

3. Jiangsu New Medical College (Ed.) (1977) Encyclopedia of Chinese Materia Medica (Appendix). Shanghai People's Press. Shanghai, 595-596.

4. Yang EJ, Lee JS, Yun CY, Kim JH, Kim JS, et al. (2008) Inhibitory effects of Duchesnea chrysantha extract on ovalbumin-induced lung inflammation in a mouse model of asthma. J Ethnopharmacol 118: 102-107.

5. Chen MH (2008) Studies on Fritillaria Cirrhosa D. Don and its effects of antitussive and antiasthma. Qinghai Normal University.

6. Yan XY (2005) Effect of ethanol extract of three kinds of Bulb Fritillariae cirrhosae on guinea pigs with allergic asthma. Sichuan University.

7. Wang D, Wang S, Chen X, Xu X, Zhu J, et al. (2012) Antitussive, expectorant and anti-inflammatory activities of four alkaloids isolated from Bulbus of Fritillaria wabuensis. J Ethnopharmacol 139: 189-193.

8. Wang D, Zhu J, Wang S, Wang X, Ou Y, et al. (2011) Antitussive, expectorant and anti-inflammatory alkaloids from Bulbus Fritillariae Cirrhosae. Fitoterapia 82: $1290-1294$.

9. Jiang Y, Li H, Li P, Cai Z, Ye W (2005) Steroidal alkaloids from the bulbs of Fritillaria puqiensis. J Nat Prod 68: 264-267.

10. Xu SY, Bian RL, Chen X (1991) Pharmacological Experiment Methodology People's Medical Publishing House, Beijing, 1167.

11. Zhang JL, Wang H, Pi HF, Ruan HL, Zhang P, et al. (2009) Structural analysis and antitussive evaluation of five novel esters of verticinone and bile acids. Steroids 74: 424-434.

12. Mo ZJ, Tang XY, Sun Z, Li W (1998) Comparison of Pharmacological Effects Between Cultispecies Sichuan Fritillary Bulb (F. wabueasis, F. mellea) and Wild Sichuan Fritillary Bulb (F. unibracteata). China Journal of Chinese Materia Medica 23: 14-16. 